\title{
Technologies for the Extraction, Separation and Purification of polyphenols - A Review
}

Shyam Suwal ${ }^{1^{*}}$ and Alice Marciniak ${ }^{2}$

${ }^{1}$ Department of Food Science, Faculty of Science, University of Copenhagen, Rolighedsvej Denmark 2Institute of Nutrition and Functional Foods (INAF), Department of Food Sciences, Université Laval,

Québec, Canada

\begin{abstract}
Polyphenols are high molecular weight, organic molecules mainly found in plant kingdom. They are mostly known for their positive impact on health, specifically for their antioxidant activity. Indeed, they are widely studied for the prevention of multiple diseases such as cancer, inflammatory, cardiovascular and neurodegenerative diseases. Nevertheless, extractions of these growing interest molecules remain challenging using conventional methods such as solvent extraction. That is why recent researches have focused on improving the extraction of polyphenol by using different technologies such as ultrasound, microwave, pressurized liquid, pulsed electric field, supercritical fluid and high hydrostatic pressure. In the current context, the assistedextraction should demonstrate their potential to improve the extraction efficiency while being cost-effective and with a low environmental impact. To this end, technologies ought to, for instance, increase the solubility of polyphenol and the permeability of the cell wall. Consequently, this review is focused on the use and potential of these technologies to improve polyphenol extractions from plants as well as their purification using various methods. It discusses of the advantages and disadvantages with some examples of all these technologies assisted-extraction in comparison with conventional extraction method as well as purification technology.
\end{abstract}

Keywords: Polyphenols, Conventional extraction process, Emerging technologies

*Corresponding Author

Email: shyam@food.ku.dk

\section{Introduction}

The prevention and treatment of chronic diseases mainly cardiovascular diseases (CVD) and cancer are the major challenge in modern day health care system. About $60 \%$ of deaths were caused by the chronic diseases in 2001 and according to the study of World Health Organization (WHO) the heart disease will overcome the infectious disease by 2020 [1]. Therefore, the burden (economical as well as social) of chronic diseases is huge and tends to increase day by day alarming an urgent need of preventive measures. Undoubtedly, the primary cause of these diseases is associated with unhealthy diets.

There is an increasing interest in diets and nutrition which has resulted in an increased importance and beliefs in functional foods and nutraceuticals [2]. Several bioactive molecules (peptides, vitamins, polyunsaturated fatty acids and polyphenols) have been isolated from food sources of plant as well as animal origin and are claimed to possess health benefits against CVD and cancer [3-5]. Very diverse nature of polyphenol in their chemical composition and their wide spread prevalence in edible plant make them very interesting as an ingredient of functional foods or nutraceuticals [3]. Different beneficial roles on human health such as antihypertensive anticancer, neuroprotector etc. have been confirmed [6]. Therefore, an immense interest of researchers on polyphenols mainly in their physiological roles (both in vitro and in vivo), their extraction processes and product development in an industrial scale can be noticed. However, extraction of such molecules from the complex plant matrices is the rate limiting factor. Several methods of polyphenol extraction from variety of food and food by-products exist such as solvent (Soxhlet), ultrasound assisted, microwave assisted, pressurized liquid, pulse electric field, supercritical fluid and high hydrostatic pressure extractions. The extraction methods not only affect the input cost, final productivity and purity but also their biological activity in laboratory assay $[7$, 8]. A cost effective and environment friendly method are thus desired for the isolation of polyphenols. A separation and purification process is another vital step in product development with polyphenols. Therefore, the 
present study aims to review different techniques used for the isolation of

\section{Flavonoids}<smiles>Cc1cc(C)c2c(c1)OC(c1cc(C)c(C)c(C)c1)=CC2</smiles>

Stilbenes<smiles>Oc1ccc(/C=C/c2cc(O)cc(O)c2)cc1</smiles><smiles>C=C(/C=C/c1ccc(O)c(O)c1)O[C@]1(C)C[C@@](C)(C(=O)O)C[C@](C)(O)[C@H]1O</smiles>

Chlorogenic acid

\section{Lignans}<smiles>COc1cc(CC(CO)C(CO)Cc2ccc(O)c(OC)c2)ccc1O</smiles>

Figure 1: Chemical structure of principal polyphenols (adapted from [3]). .

polyphenols published in the literature. In addition, methods of fractionation and purification of extracted polyphenol or free polyphenols present in liquid beverages are also discussed

\section{Polyphenols and health claims}

Polyphenols are readily available in the plantderived food sources consumed by human in daily basis such as fruits, vegetables, cereals, tea, wine etc. [3]. They are responsible for the major organoleptic properties such as color and taste of plant-derived food and beverages [9]. Plant polyphenols comprise of diverse groups of compounds that make them difficult to be characterized except for some well-known ones whose structure, chemical composition and functionality are well defined. Ample of polyphenol structures (having several hydroxyl groups in aromatic ring) are found in plants are therefore classified according to the number of phenol rings to one another. They can be mainly classified into the phenolic acids, flavonoids (flavones, anthocyanidins), stilbenes, and lignans (cinamic acid) as shown in figure 1. Each of these phenolic compounds can be subclassified according to the type of heterocycle involved. The chemical nature of phenolic compound can vary from a simple to polymerized structure and may be found in a complex form with some carbohydrate, protein or plant substances making them highly insoluble [10]. Furthermore, a single may contain several polyphenols whose concentration (several $\mathrm{mg}$ to few g per $\mathrm{kg}$ or $\mathrm{L}$ ), stability and activity vary from one to another. More than 8000 phenolic compounds are known to exist and about 4000 flavonoids have been identified [11]. Further details about different type of phenolic compounds in food sources, their characteristics and relevance can be found in the literature [3, 12].

Polyphenols are very well known as the most abundant antioxidant in the diet and they have been claimed to possess potential benefits against cardiovascular diseases, cancer and neurodegenerative diseases in vitro as well as in vivo $[6,13,14]$. Due to the vast structural diversity of polyphenols many of them have not yet been identified and characterized consequently the functional mechanism are not well established. Amongst them, the tea polyphenol: catechin also known as epigallocatechin-3-gallate (EGCG) is well characterized and a large number of researches are focused on its mode of action. Lorenz [14] discussed the different mechanisms of 
anticancer (apoptosis, inhibition of tumor growth and inhibition of telomerase), antioxidant (free radical scavenging, chelation of metal ions, inhibition of ROS producing enzyme and reduction of inflammatory cytokines), antihypertensive (vasodilation) and neuroprotective (antineuro inflammatory effect, activity of EGCG in the cellular and molecular levels. In addition, a detail pharmacokinetic study (absorption, distribution metabolism and elimination) of tea polyphenols is recently reviewed by Clifford et al. [15].

\section{Extraction process}

Due to positive effects on human health, phenolic compounds (isolated form or in extract) could be used as food supplements (functional food) or nutraceuticals. To do so, a cost-effective methods for the extraction and separation of polyphenols is necessary. A lot of research has focused on the analysis of biological activities and characterization of phenolic compound and the extraction process are often ignored. The extraction and isolation of polyphenols remain challenging especially due to structural complexity and instability (degradation and reaction during processing) $[9,11]$. Therefore, the efficiency of the extraction of phenolic compounds from plant material are influenced by several parameters: the chemical nature and location within the plant matrix of the phenolics, the extraction method used, the size of sample particle, storage conditions and presence of interfering substance and consequential biochemical and chemical reactions [10, 16]. Phenolic compound are essentially found in cell walls, vacuoles, associated with nuclei, leaves, gymnosperm and rhizomes [17]. In addition, most of the phenolic compounds in plant sources are bound to plant material by covalent bond making it a real challenge to liberate them into the extractable form [18]. Therefore, different extraction methods have been developed in this domain. The rate limiting step for phenolic compound extraction from plant material is the (a) solubility, (b) diffusibility through the cell walls and (c) washing out (rinsing) of the cell wall $[16,19]$.

\section{Conventional Solvent extraction}

Solvent extraction (SE) is one of the conventional methods of extraction of bioactive molecules from plant sources but is still widely used for the extraction of various natural bioactive compounds specially the phenolic compounds from various sources [20]. Pretreated plant material (washing, drying, etc.) are exposed to varieties of solvents such as, water, hexane, ether, chloroform, acetonitrile, benzene, ethanol and methanol which take up the molecules of interest (polyphenols). However, the efficiency of solvent extraction methods is affected by the solvent used (solubility of phenolic compounds depend on the solvent type or its polarity) and the nature of phenolics (degree of polymerization) and their interaction with other plant or food constituents [10]. The choice of extraction techniques have to take into consideration of the location of phenolic compounds in the plant, most of which are stored in the vacuoles only extractable by alcoholic or organic solvents except that are bound to insoluble carbohydrate or protein [21]. Soxhlet extraction also known as solid-liquid extraction is one of the first techniques known to be used for the extraction of polyphenols compounds [22]. This technique is more often considered as a leaching or lixiviation. The working principal of Soxhlet apparatus is simple as shown in figure 2 . The sample is placed in a thimble-holder and solvent (extractant) and is filled with condensed solvent from a distillation flask. A siphon aspirator is used to unload the excess of solvents when it reaches to overflow level that carries the extracted molecules to the bulk liquid. This process is repeated until a complete extraction is achieved. 


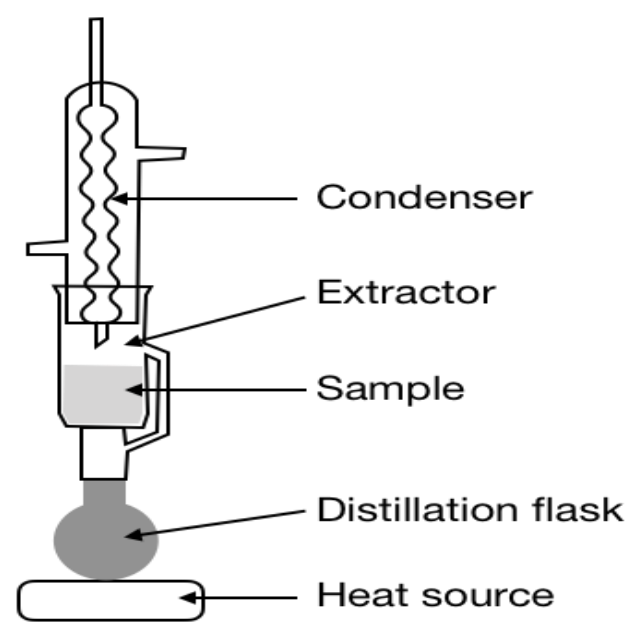

Figure. 2: Conventional Soxhlet extractor (adapted from [23])

The Soxhlet extraction process is easy to operate not requiring any professional expertise. In addition, extraction productivity could be increased by simultaneous extraction in parallel and further treatment such as filtration is not required as no plant residues are present. However this method of extraction is often criticized as a large volume of solvent used which eventually cause environmental problems in addition to higher cost involved, long treatment period and thermal degradation (due to excessive exposure to heat during extraction and evaporation post extraction) of extracted molecules as the extraction is carried out at boiling point of solvent [22]. In addition, excessive exposure to light and oxygen lead to the degradation of other sensitive compounds [24]. Therefore, various other improved methods of solvent extraction are researched and rapidly being developed which mainly focus on decreasing the quantity of organic solvent, treatment time and energy and increase the yield. These methods are discussed in the following sections in details.

\section{Novel and emerging methods of extraction}

\subsection{Ultrasound assisted extraction}

The use of ultrasound (wave frequencies of more than $20 \mathrm{kHz}$ to $10 \mathrm{MHz}$ ) in the extraction of bioactive molecules known as ultrasound-assisted extraction (UAE) are believed to reduce the organic solvent, find other alternative solvents which are economically, environmentally sound and safe to human health [25].

The irradiation of plant tissues with ultrasound increase the number of extraction solvent exposed to the molecules by breaking down the cell wall, increasing swelling and hydration degree thus improving the diffusion and mass transfer [19]. The use of UAE have been found to improve the extraction efficiency up to $35 \%$ during the extraction of phenolic compounds from various plant sources [25]. Chen et al. [26] found an optimized condition of UAE treatment (solvent to solute ratio of $4: 1(\mathrm{ml} / \mathrm{g})$, extraction time $200 \mathrm{~s}$ and ultrasonic power was $400 \mathrm{~W}$ ) and found 3.45 $\mathrm{mg}$ of anthocyanins per gram of fresh raspberries at moderate temperature (less than $40^{\circ} \mathrm{C}$. Another study was carried out for the retention (stability) of anthocyanins in grape juice as function of ultrasound amplitude during ultrasound treatment [27]. At higher amplitude and treatment time degradation of certain anthocyanins were observed due to the mechanism called sonolysis of water molecules due to cavitation inducing the formation of hydroxyl radicals which eventually lead to chemical degradation. A comparative study of different method of extraction namely UAE, high hydrostatic pressurized extraction (HHPE) and pulse electric field (PEF), which will be discussed later, showed higher total phenolic content as compared to that of control (water as solvent at $70{ }^{\circ} \mathrm{C}$ ) [28]. But least yield and antioxidant activity was observed in case of UAE as compared to HHPE and PEF. However, no reason was discussed for the least antioxidant activity observed. This could be large quantity of plant residues (impurities) present in the extracts.

UAE is a non-thermal process which could be easily integrated to other existing methods without major modification to improve the extraction efficiency and yield. Therefore, the main advantage of UAE over other technique could be mild temperature thus minimum thermal degradation [29]. However, the drawback of this technique is the requirement of post treatment like filtration to get rid of resulting plant residues during the process and inability to reuse the extraction solvent [22]. 


\subsection{Microwave assisted extraction}

Microwave assisted extraction (MAE), developed in 1980s, is a process which involves the heating of solvent by in contact with sample with microwave energy to partition the molecules of interest from plant matrix to the solvent used [30]. In comparison to other traditional extraction method, MAE possesses advantages like shorter time, controlled temperature and other extraction environment, less solvent, higher extraction rate, energy saving and better quality product (higher antioxidant activity) with lower cost [31]. In addition, MAE method could adapt easily the already existing extraction process for example that of Soxhlet. The extraction method is different from other conventional method because the extraction occurs due to the changes in cell structure caused by electromagnetic waves [32]. Unlike the conventional method where the heat is transferred from the solvent to the interior of sample, in MAE the heat is dissipated volumetrically inside the irradiated medium therefore the distribution of temperature is equal all over the sample

The increase in free phenolic acid content with increase in microwave power and treatment time was observed in citrus mandarin pomace and peels consequently increasing their antioxidant capacity $[33,34]$. This study also demonstrated that at $250 \mathrm{~W}$ of microwave power, the total flavonoid compounds decreased with increase in the duration of treatment suggesting a possible degradation due to longer exposure to heat. Therefore, microwave treatment could be economically viable, rapid and used in an industrial scale production but careful choice of heating temperature and duration is needed.

\subsection{Pressurized liquid extraction}

A pressurized liquid extraction (PLE) method which is comparatively a new method, is operated at elevated temperature $\left(50\right.$ to $200^{\circ} \mathrm{C}$ ) and pressure (3.5 to $20 \mathrm{MPa}$ ) and is supposed to enhance the extraction efficiency as compared to conventional methods carried out at room temperature and atmospheric pressure [16]. This technique uses a solid samples packed in an extraction cell and uses organic solvent or water at high pressure and temperature above the boiling point [35]. A typical instrumental set up of a pressurized liquid or fluid extraction (PLE) is shown in figure 3 . The system consists of a pumping system for the supply of solvent from the solvent vessel which enters to a heating system to increase the temperature of the solvent, an extraction cell containing sample, a back pressure controller and a collector at the end [35].

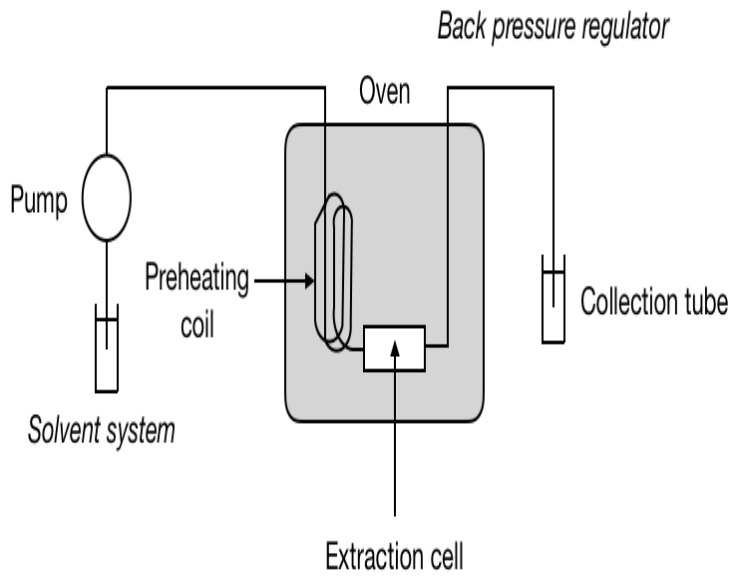

The extraction efficiency using PLE are improved by increasing the solubility of phenolic compounds and mass transfer to the extracting solvent. [36]. In addition, increasing the pressure at elevated temperature, the diffusivity of a solvent could be increased which will better penetrate through the plant matrix and disrupt the solute-matrix interaction due to der Waals forces, hydrogen bonding and dipole attractions between solute molecules and active sites on the matrix [37].

In the study of Denery et al. [24] similar extraction efficiency of caretenoids were observed using PLE and conventional (which used only sonication and centrifugation) extraction method reducing the extraction solvent by 50\% and extraction time by about $77 \%$. In addition, PLE was advantageous for the oxygen and light liable carotenoids.

Fig. 3: Schematic diagram of pressurized liquid extraction system adapted from [35]

The thermal degradation which even favors the oxidation of phenolic compound such as anthocyanins could be main issue related to PLE. However, Palma et al. [38] have demonstrated that among 9 phenolic compounds tested most of 
them are stable except for catechin and epicatechin at $150{ }^{\circ} \mathrm{C}$ and maintain the recovery rate above $85 \%$ with methanol as extracting solvent. Similar result was observed by Piñeirol et al. [39] during the extraction of catechin and epicatechin from tea leaves and grape seeds with recovery rate below $95 \%$ at $130^{\circ} \mathrm{C}$. However, this study demonstrated the best recovery of catechin and epicatechin from grape seeds using PLE using methanol as solvent as compared to simple stirring assisted extraction and UAE.

Water is an extremely polar solvent, therefore not usually used as solvent for the extraction of organic compounds. However, water is nonflammable, non-toxic, widely distributed ecological solvent [36]. At high temperature and pressure water can act as good solvent as the polarity approaches (decreases) to that of alcohols. To maintain the water in liquid state a pressure ranging from 15 (at $200^{\circ} \mathrm{C}$ ) to 85 (at $\left.300^{\circ} \mathrm{C}\right)$ bars has to be applied [37]. Therefore, pressurized hot water extraction (PHWE) method is getting interest in the extraction of bioactive molecules from plant and food material. It could also be possible to combine the PLE with PHWE in order to increase the efficiency of extraction process. The temperature of solvent, pressure applied and extraction time vary widely depending strongly upon the type of phenolics, the solvent used and extraction instrument. Therefore, at this stage nothing could be concluded about the optimum PLE parameters (time, solvent, pressure and temperature).

\subsection{Pulsed Electric field}

Pulsed electric field (PEF) is one of the newest technologies developed as a non-thermal process which have been widely studied in the food processing sectors. Pretreatment of plant material with PEF enhance the extraction of bioactive molecules by electro-permeabilization (also known as electroporation) of plant cell increasing the mass transfer even at lower electric field [40]. Biological membrane plays an important role to amply the electrical signal as it is more conductive as compared to its surrounding environment (cytoplasm and extracellular medium). The mechanism of electroporation is shown in the figure 4. When an external electric field (E) is applied to a cell with certain thickness, the electrical potential across the membrane (called transmembrane electric field, which is far greater than applied electric field) increases and when the E exceeds the critical value a reversible or irreversible pores are formed. Effectively, the number pore formation depends directly on the electric field applied as well as the number of pulse.

A significant improvement by $21.5 \%$ and $28.6 \%$ in anthocyanins content in wine with the grape skin pretreated with PEF (50 pulses and $1 \mathrm{~Hz}$ ) using 5 and $10 \mathrm{kV} / \mathrm{cm}$ electric fields as compared to that of untreated one was shown by López et al. [41]. In addition, application of PEF (50 pulses at $122 \mathrm{~Hz}$ ) at $5 \mathrm{kV} / \mathrm{cm}$ electric field have shown to maintain higher anthocyanins and polyphenols concentration during the aging process of red wine

[42]. Furthermore, treatment with PEF of merlot grapes was found to improve the sensorial and visual quality of wine in addition to increase in the polyphenols and anthocyanins [43, 44]. The four fold increase in antioxidant activity was observed for PEF ( 30 pulses, $2 \mathrm{~Hz}$ and $3 \mathrm{kV} / \mathrm{cm}$ ) treated grape as compared to untreated grape byproducts [28]. The increase in antioxidant activity was directly related to significant increase in phenolics as compared to the untreated samples. Therefore, PEF can be regarded as a promising tool for valorization of low cost industrial waste to nutraceuticals or functional food. The PEF treatment to enhance the extraction and increase the phenolic compound concentration during maceration and fermentation process of red wine making is extensively researched. 


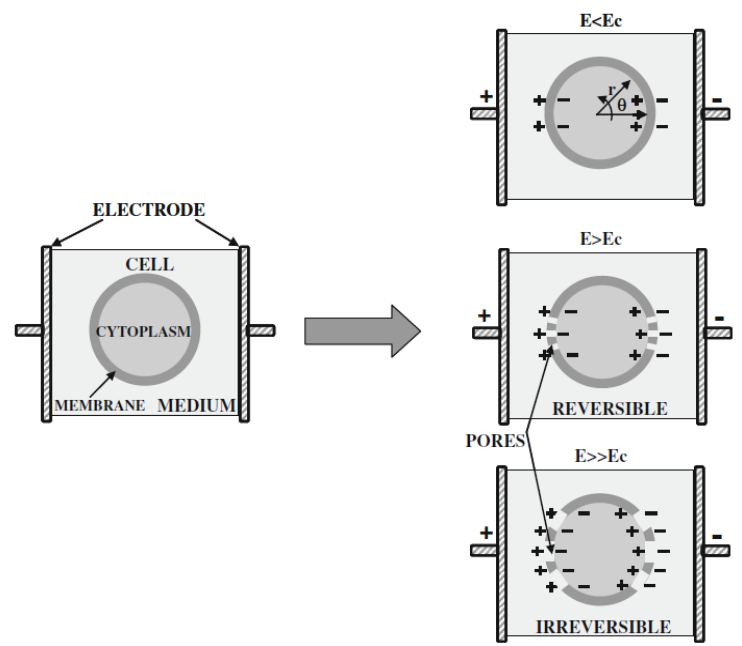

Fig. 4: Mechanism of electroporation of biological membrane in an external electric field $(E) . E_{c}$ represent the critical value of electric field applied (adapted from [40]).

\subsection{Supercritical fluid extraction}

Supercritical fluid extraction (SFE) has been widely used in large scale in order to extract natural solid materials especially for food ingredients, supplementation and phytopharmaceuticals. SFE is getting its popularity due to a very low or no organic solvent, innovative, high valued and quality final product, reduced extraction time and higher selectivity but often criticized for high investment cost $[45,46]$. At the critical values of pressure and temperature a fluid behaves like a supercritical fluid having an intermediate properties (diffusivity, solubility and density) of gas and liquid [46]. Carbon dioxide and water are most widely used as supercritical fluid. In comparison to water $\mathrm{CO}_{2}$ is comparatively easier to operate and commonly used as it has a moderate critical temperature $\left(31.2^{\circ} \mathrm{C}\right.$ as compared to $101.1^{\circ} \mathrm{C}$ for water) and pressure (72.9 atm vs. $217.6 \mathrm{~atm}$ for water). In addition, $\mathrm{CO}_{2}$ is generally regarded as safe (GRAS) and does not leave the residue after extraction simply by depressurization at room temperature. However, $\mathrm{CO}_{2}$ is not very suitable for extraction of highly polar compounds (such as flavonoids) as polarity of $\mathrm{CO}_{2}$ is lower thus, other solvent (e.g. methanol and ethanol) at low concentration could be used as co-solvent, known as modifiers, which subsequently increase the extraction efficiency. Le Floch et al. [47] used supercritical $\mathrm{CO}_{2}$ extraction using methanol as modifiers to extract polyphenols from olive leaves at different temperature, pressure, concentration of modifiers and extraction time. The phenolic content increased with temperature, pressure and concentration of modifiers but a plateau was observed at 140 minutes. At the same time, a comparison was made with a UAE with different solvents. The SFE with 10 \% modifier (methanol) gave rise higher phenolic concentration as compared to UAE with low polarity solvent (nhexane, diethyl ether or ethyl acetate) but significantly lower as compared to UAE with high polarity solvent (methanol).

Only $45 \%$ extraction efficiency was observed using SFE. Another comparative study for the extraction of isoflavones from soybean flour were conducted between SFE $\left(\mathrm{CO}_{2}\right)$ with methanol as modifiers (10\%), soxhlet (80\% ethanol) and UAE (70 \% methanol) [56]. As before, a strong interaction between pressure and temperature was noticed. Similarly, least amount of isoflavones $(86.28 \mu \mathrm{g} / \mathrm{g}$ of dry weight) were extracted using SFE than UAE $(311.55 \mu \mathrm{g} / \mathrm{g})$ and Soxhlet

(212.86 $\mu \mathrm{g} / \mathrm{g})$. Despite of lower recovery of isoflavones using SFE techniques, it was the most selective process as very less co-extracts were present and require fewer steps for the extraction. Moreover, the selectivity of the SFE process was further proven by the results found by Kitzberger et al. [57] who demonstrated that only the shiitake mushroom extracts (which contained flavonoids) obtained by SFE (at $40^{\circ} \mathrm{C}, 20 \mathrm{MPa}$ and $15 \%$ ethanol) with ethanol as a co-solvent had an antibacterial activity against Micrococcus luteus and Bacillus cereus as compared to the conventional extraction with $n$-hexane, ethyl acetate and dichloromethane. However, the antibacterial activity was supposed to be due to selective extraction of flavonoids with SFEethanol however, the authors did not compare the results with conventional extraction with only ethanol as solvent. Thus, it was not clear if the selective extraction of flavonoids and thus bioactivity was dependent on extraction technique or also with the type of solvent (more polar solvent like ethanol. Therefore, SFE technique undoubtedly carries a huge application 
on polyphenols extraction but considerable innovations are needed for their industrial and economic feasibility.

\subsection{High hydrostatic pressure}

High hydrostatic pressure is a non-thermal and green process governed by Le Chatelier's principle (Mozhaev 1994). While first application of HHP dates from few decades, the technology is considered as an emerging process since the first industrial-scale systems were available in 1990 in Japan. High hydrostatic pressure processing consists to apply a uniform pressure (100 - 1000 $\mathrm{MPa}$ ) which is instantaneously and uniformly transmitted, independent of the size and geometry of food, on flexible packaging materials filled with liquid or solid food products. The pressure transmitter fluid is generally water and the process can be used with or without utilization of heat. Its main application concerns the pasteurization of food product in order to improve their shelf-life and preserve components of a wide range of food products. Nowadays, a large number of studied focused on innovative applications of HHP such as the improvement of polyphenol's extraction.

Jun et al., (2009) compared the assisted extraction of polyphenol from green tea leaves by HHP (HHPE) with conventional methods, using different solvents, pressure parameters and ratio liquid:solid. They stated an increase of polyphenol extraction yields is governed by an increase in pressure level (from 15 to 30\% from 100 to 600 
Table 1: Methods of polyphenol extraction from different food sources and byproducts.

\begin{tabular}{|c|c|c|c|}
\hline Source & Extraction method & $\begin{array}{lll}\text { Total phenolic content } \\
(\mathrm{mg} / \mathrm{g}) \text { or } \mathrm{mg} / \mathrm{ml}\end{array}$ & Reference \\
\hline Citrus mandarin peels & MAE-methanol & $6.37 \pm 0.200$ & {$[34]$} \\
\hline Citrus mandarin pomace & MAE-methonol & $6.18 \pm 0.12$ & [33] \\
\hline Medicinal plant-Lien Tze Hsin & IL-MAE-methanol & $15.76 \pm 0.329$ & [48] \\
\hline Peanut skin & MAE-ethanol & 144 & [49] \\
\hline Grape marcs & SE-ethanol & 28.06 & {$[50]$} \\
\hline Blueberry & SE-ethanol (50\%) & 1.48 & [51] \\
\hline Lemon peel & Enzyme -assisted & $1.13 \pm 0.0076$ & {$[52]$} \\
\hline Black tea & $\begin{array}{l}\text { Solvent-acetone } \\
\text { - } N, N \text {-dimethylformamide } \\
\text {-ethonol } \\
\text {-methanol }\end{array}$ & $\begin{array}{l}98.19 \pm 1.10 \\
109.36 \pm 0.71 \\
86.31 \pm 3.50 \\
68.69 \pm 1.34\end{array}$ & [8] \\
\hline Algae and Cynobacteria & PLE-SPE & - & {$[53]$} \\
\hline Green algae & PLE (1500-2000 psi) & 11.4 & {$[24]$} \\
\hline Herbal medicine (Epimedium sp.) & PLE- 70\% ethanol (1500Psi) & 48.51 & {$[54]$} \\
\hline $\begin{array}{l}\text { Grape seeds } \\
\text { Tea leaves }\end{array}$ & PLE-methanol & $\begin{array}{l}1.82 \\
0.65 \\
0.62 \\
3.31\end{array}$ & [39] \\
\hline Raspberries & UAE $(200 W), 22 \mathrm{kHz}$ & 3.45 & [26] \\
\hline Grape seeds & UAE (200W), $24 \mathrm{kHz}$ & $\begin{array}{l}0.23 \\
0.07\end{array}$ & [39] \\
\hline Grape skin & $\begin{array}{l}\text { PEF (50 pulses, } 122 \mathrm{~Hz})- \\
5 \mathrm{kV} / \mathrm{cm} \\
-10 \mathrm{kV} / \mathrm{cm}\end{array}$ & $\begin{array}{l}9.65 \\
10.6\end{array}$ & {$[41]$} \\
\hline Red grapes & $\begin{array}{l}\text { PEF (50 pulses, } 122 \mathrm{~Hz})-5 \\
\mathrm{kV} / \mathrm{cm} \\
-7 \mathrm{kV} / \mathrm{cm}\end{array}$ & $\begin{array}{l}6.02 \\
5.20\end{array}$ & [55] \\
\hline Grape byproduct & $\begin{array}{l}\text { PEF (30 pulses, } 2 \\
3 \mathrm{kV} / \mathrm{cm})\end{array}$ & 61.2 & {$[28]$} \\
\hline Olive leaves & $\begin{array}{l}\text { SFE-10\% methanol, } 330 \mathrm{~atm} \\
\text { and } 100{ }^{\circ} \mathrm{C}\end{array}$ & $7.6 \pm 0.5$ & [47] \\
\hline Soybean flour & $\begin{array}{l}\text { SFE-10\% methanol, } 355 \mathrm{~atm} \\
\text { and } 50 \circ \mathrm{C}\end{array}$ & 0.086 & [56] \\
\hline Shiitake mushroom & $\begin{array}{l}\text { SFE-15 \% ethanol, } 296 \text { atm } \\
\text { and } 50 \circ \mathrm{C}\end{array}$ & 10.2 & [57] \\
\hline Grape skin & HHP-50\% ethanol (200 MPa) & $8.91 \pm 0.13$ & {$[58]$} \\
\hline Chilean papaya seeds & $\begin{array}{l}\text { HHP-500 } \mathrm{MPa} 15 \mathrm{~min} 50 \% \\
\text { ethanol }\end{array}$ & - & [59] \\
\hline Green tea leaves & $\begin{array}{l}\text { HHP-500 } \mathrm{MPa} 1 \mathrm{~min} 50 \% \\
\text { ethanol }\end{array}$ & - & {$[60]$} \\
\hline Watercress & $\begin{array}{l}\text { HHP-600 MPa } 3.1 \mathrm{~min} 100 \% \\
\text { ethanol }\end{array}$ & $64.68 \pm 2.97$ & [61] \\
\hline
\end{tabular}

$\mathrm{MPa}$ ). Globally, they achieve in $1 \mathrm{~min}-500 \mathrm{MPa}$ reach the same conclusion concerning the the same extraction yield obtained by $90 \mathrm{~min}$ ultrasonic extraction, $45 \mathrm{~min}$ heat reflux extraction or $20 \mathrm{~h}$ room temperature extraction. More recently, a research on Chilean papaya seeds have efficiency of HHP to improve the extraction of polyphenol. Indeed, Briones-Labarca et al., (2014) could extract more efficiently polyphenol by $\operatorname{HHPE}(5,10$ and $15 \mathrm{~min})$ in comparison with 
conventional extraction (30 min) or even ultrasound assisted-extraction (5,10 and $15 \mathrm{~min})$. Lastly, Pinela et al., (2018) determined by response surface methodology, the optimal HHPE parameters to achieve the higher extraction yields of polyphenol from watercress. Once again, there is a significant positive correlation between the level of pressure and the extraction yield. Broadly speaking, HHP enable the solvent to enter cells and lead to an increase of the cell permeability. During the instantaneous release of pressure, the cell wall is disrupted leading to a spill of cytoplasm and target molecules such as polyphenols (Jun et al., 2009). The different methods of extraction process used for polyphenol extraction from various food sources and their by-products are summarized in Table 1. To this point, it is not very clear which is the best extraction method due to the complexity in plant source, wide nature of polyphenols (size and physicochemical) and varieties of solvent used. Various studies made the comparison among different methods. However, the same method showed different yield which largely depended on type of source and solvent used. Table 2 shows the comparison between different extractions methods discussed above. Therefore, more comprehensive studies are needed that can clearly distinguish the mechanism of extraction and its relation to different type source, molecules of interest, time and cost.

\section{Separation and purification processes 4.1 Ion exchange chromatography}

Ion exchange chromatography (IEC) is widely used technique in food processing which separates the molecules according to their charge [62]. The later can be modified by changing the $\mathrm{pH}$ or ionic strength of the solution. Ottens et al. [62] emphasized that for a preparative purification of bio-molecules an IEC process in indispensable that need to take into consideration of the choice of resins, the adsorbent (cost, resin capacity, regeneration cycle, life time and safety). Adsorption and desorption of molecules to be separated (target molecules) on resins packed in a column are the main steps in the IEC process. Equilibration of resins $(\mathrm{pH}$, ionic strength and solvent concentration), loading of samples with impurities (that will adsorb onto the resin), washing (to desorb the impurities) and elution (of target molecule to elution buffer) that can be carried out in isocratic or gradient mode, are the main steps of a typical IEC process.

A high recovery efficiency of EGCG was found by using cyclic IEC techniques that uses less volume of solvents $(30 \%$ ethanol) as compared to conventional maceration extraction using ultrasound [63]. Anthocyanins from strawberry were purified by IEC using Amberlite XAD-7 as ion exchange resin before analytic separation [64]. Similarly, cation exchange chromatography technique was used to purify polyphenols from red wine after solvent extraction [65]. As this technique uses solvents as an eluent to desorb the adsorbed polyphenols from the ion exchange resin further purification is needed to ensure the purity of the final product. In addition, the use of non-solvent IEC process could be a better option. Polyphenols such as epigallocatechin-gallate (EGCG), epicatechin-gallate (ECG) and epigallocatechin (EGC) were separated by using weakly acidic cation exchange gels (dextran based) from crude tea extracts without using any solvent [66]

\subsection{Membrane based process}

A membrane based separation process has been widely used in an industrial scale. In addition, all the above mentioned extraction processes contained more or less organic solvent which are proven to be toxic to human health, thus has an important role in consumer acceptance of these product. In addition, the separation and purification efficiency of membrane process depends upon the molecular weight polyphenols to be concentrated which ranges from 290 to 1200 $\mathrm{g} / \mathrm{mol}$, membrane molecular weight cut off (MWCO) sizes and the transmembrane pressure (the driving force) applied in the system. Generally, ultrafiltration (UF), nanofiltration (NF) and reverse osmosis ( $\mathrm{RO}$ ) process are used. The membrane process are particularly interesting to separate and concentrate polyphenols from or in 


\begin{tabular}{|c|c|c|c|c|c|c|c|}
\hline & Solvent extraction & $\begin{array}{c}\text { Microwave } \\
\text { assisted } \\
\text { extraction }\end{array}$ & $\begin{array}{l}\text { Supercritical fluid } \\
\text { extraction }\end{array}$ & $\begin{array}{l}\text { Ultrasound- } \\
\text { assisted extraction }\end{array}$ & $\begin{array}{l}\text { Pulsed electric } \\
\text { field }\end{array}$ & $\begin{array}{c}\text { Pressurized } \\
\text { solvent extraction }\end{array}$ & $\begin{array}{c}\text { High Hydrostatic } \\
\text { Pressure } \\
\text { extraction }\end{array}$ \\
\hline Brief description & $\begin{array}{l}\text { Solvent is heated } \\
\text { by a conventional } \\
\text { oven } \\
\text { and passed by the } \\
\text { sample }\end{array}$ & $\begin{array}{l}\text { Immersion of the } \\
\text { sample in } \\
\text { solvent and } \\
\text { microwave energy } \\
\text { is submitted }\end{array}$ & $\begin{array}{l}\text { A high pressure } \\
\text { vessel is filled with } \\
\text { sample and crossed } \\
\text { continuously by } \\
\text { the supercritical } \\
\text { fluid }\end{array}$ & $\begin{array}{l}\text { Immersion of the } \\
\text { sample in solvent } \\
\text { and submission to } \\
\text { ultrasound using a } \\
\text { US probe or US } \\
\text { bath }\end{array}$ & $\begin{array}{l}\text { Pulses of high } \\
\text { electric } \\
\text { voltages are } \\
\text { applied to the } \\
\text { sample placed } \\
\text { in between } \\
\text { two electrodes }\end{array}$ & $\begin{array}{l}\text { Heat of the sample } \\
\text { by a conventional } \\
\text { oven and crossed } \\
\text { by the extraction } \\
\text { solvent under } \\
\text { pressure }\end{array}$ & $\begin{array}{c}\text { Sample is } \\
\text { pressurized (100 - } \\
1000 \mathrm{MPa}) \\
\text { through a } \\
\text { pressure } \\
\text { transmitter liquid }\end{array}$ \\
\hline Extraction time & 6-8 hours & $3-30 \mathrm{~min}$ & $10-60 \mathrm{~min}$ & $10-60 \mathrm{~min}$ & - & $10-20 \mathrm{~min}$ & $1-30 \mathrm{~min}$ \\
\hline Sample size & - & $1-10 \mathrm{~g}$ & $1-5 \mathrm{~g}$ & $1-30 \mathrm{~g}$ & & $1-30 \mathrm{~g}$ & - \\
\hline Solvent volume & - & $\begin{array}{l}10-40 \mathrm{ml} 2-5 \mathrm{ml} \\
\text { (solid trap) }\end{array}$ & $\begin{array}{c}\text { 30-60 ml (liquid } \\
\text { trap) }\end{array}$ & $50-200 \mathrm{ml}$ & - & $15-60 \mathrm{ml}$ & - \\
\hline Cost & & Moderate & High & Low & High & High & High \\
\hline Advantages & $\begin{array}{c}\text { Rapid and easy to } \\
\text { handle }\end{array}$ & $\begin{array}{l}\text { Rapid } \\
\text { Easy to handle } \\
\text { Moderate solvent } \\
\text { consumption }\end{array}$ & $\begin{array}{c}\text { Rapid } \\
\text { Low solvent } \\
\text { consumption } \\
\text { Concentration of the } \\
\text { extract } \\
\text { No filtration } \\
\text { necessary } \\
\text { Possible high } \\
\text { selectivity } \\
\end{array}$ & Easy to use & $\begin{array}{c}\text { Rapid and } \\
\text { non-thermal } \\
\text { process }\end{array}$ & $\begin{array}{c}\text { Rapid } \\
\text { No filtration } \\
\text { necessary } \\
\text { Low solvent } \\
\text { consumption }\end{array}$ & $\begin{array}{c}\text { Rapid } \\
\text { Green technology } \\
\text { High selectivity } \\
\text { High extraction } \\
\text { yield } \\
\text { No degradation of } \\
\text { target molecules }\end{array}$ \\
\hline Disadvantages & $\begin{array}{c}\text { High solvent } \\
\text { consumption, long } \\
\text { treatment time and } \\
\text { thermal } \\
\text { degradation }\end{array}$ & $\begin{array}{l}\text { Extraction solvent } \\
\text { must } \\
\text { absorb microwave } \\
\text { energy } \\
\text { Filtration step } \\
\text { required }\end{array}$ & $\begin{array}{c}\text { Many parameters to } \\
\text { optimize }\end{array}$ & $\begin{array}{l}\text { Large amount of } \\
\text { solvent } \\
\text { consumption } \\
\text { Filtration step } \\
\text { required }\end{array}$ & $\begin{array}{l}\text { Mechanism } \\
\text { not well } \\
\text { known and } \\
\text { process } \\
\text { intensification } \\
\text { is difficult }\end{array}$ & $\begin{array}{c}\text { Possible } \\
\text { degradation of } \\
\text { thermolabile } \\
\text { analytes }\end{array}$ & $\begin{array}{l}\text { High cost } \\
\text { equipment }\end{array}$ \\
\hline
\end{tabular}


aqueous solutions (fruit juices) or from the complex solute-solvent after the extraction process using conventional methods can significantly minimize the amount of solvent being used [67, 68]. The efficiency of concentration of polyphenols from grape seeds by ultrafiltration (dead end filtration) with $50 \mathrm{kDa}$ membrane was found to depend on the method of extraction used [68]. In fact, the different extraction processes result to in different quality final product in terms of solute (polyphenols) content. Significantly higher concentration (40$50 \%$ ) of total polyphenols was recovered in retentate after the ultrafiltration. The studies with different MWCO membranes have shown that low molecular weight phenolic compounds are mostly present in permeate solution however in the concentrate of reverse osmosis process [69].

Another possibility of concentration of polyphenols with higher selectivity is to use the sequential filtration process. For the low molecular free polyphenols found in olive mill wastewater (OMW) were extracted by sequential filtration process [70]. The first step, microfiltration was followed by nanofiltration and osmotic distillation (also known as isothermal membrane distillation) and vacuum membrane distillation. The preliminary step of microfiltration reduced significantly total organic carbon and $0.5 \mathrm{~g} / \mathrm{L}$ of low molecular weight polyphenols. The osmotic distillation process is relatively a new method which can potentially be used in the concentration of beverages and other liquid food stuffs. In this process, a micro-porous, non-liquid-wettable membrane (hydrophobic) separates a mixture of liquid containing a volatile in one side and a second liquid phase capable of absorbing the volatile component. Membrane distillation process could be advantageous to selectively remove the solvent (ethanol) used during the extraction process. The details about the membrane distillation process are discussed in the literature [71]. This process was used to concentrate polyphenols from olive mill wastewater using micro-porous membranes with up to $99 \%$ separation coefficient [72].

However, the membrane processes are frequently criticized due to membrane fouling and reduced selectivity for polyphenols separation. Fouling by polyphenols and therefore significant reduction in water flux was observed by Susanto et al. [73]. They proposed different mechanisms of interaction between polyphenols molecule (or aggregate of polyphenols) with membrane materials. The different interaction could be hydrophobic, hydrogen bonding and benzene ring interaction via $\Pi-\Pi$ stacking when the membrane contains benzene rings (polyethersulfone, PES). The polyphenols can reduce the size of pore or block entirely.

\subsection{Electromembrane process- Electrodialysis with ultrafiltration membrane}

Electromembrane process is widely used to separate charged molecules from a complex mixture of solution. One of the recent electromembrane processes is the combination of the conventional electrodialysis process with membrane filtration known as electrodialysis with filtration membrane (EDFM), with a diverse application in food processing, biotechnology and biopharmaceutical [74]. In this method, the electric field applied acts as the driving force for the migration of charged molecules (ionic species) across a porous membrane (microfiltration) from one solution to another. As there is no pressure applied in the system in contrast to the pressure driven filtration process, there are no or very less accumulation of solutes on the membrane surface. Bazinet et al. [75] reported the first application of electrodialysis (ED) process in the separation of polyphenols from tobacco extract. The authors successfully separated chlorogenic acid with migration rate up to $28 \%$ using in 3 hours of treatment. A significant improvement in migration rate of $90.8 \%$ for chlorogenic acid and $86.5 \%$ and $81.3 \%$ for scopoletin and rutin respectively by increasing the membrane stacks by 3 folds in the same system treated for 4 hours as shown in figure 5 [76].

Later on the EDFM process was used to separate catechins from green tea. Labbé et al. [77] successfully and selectively separated EGCG and EGC from green tea infusion by in an ED system with the migration rate as high as $50 \%$ within 1 


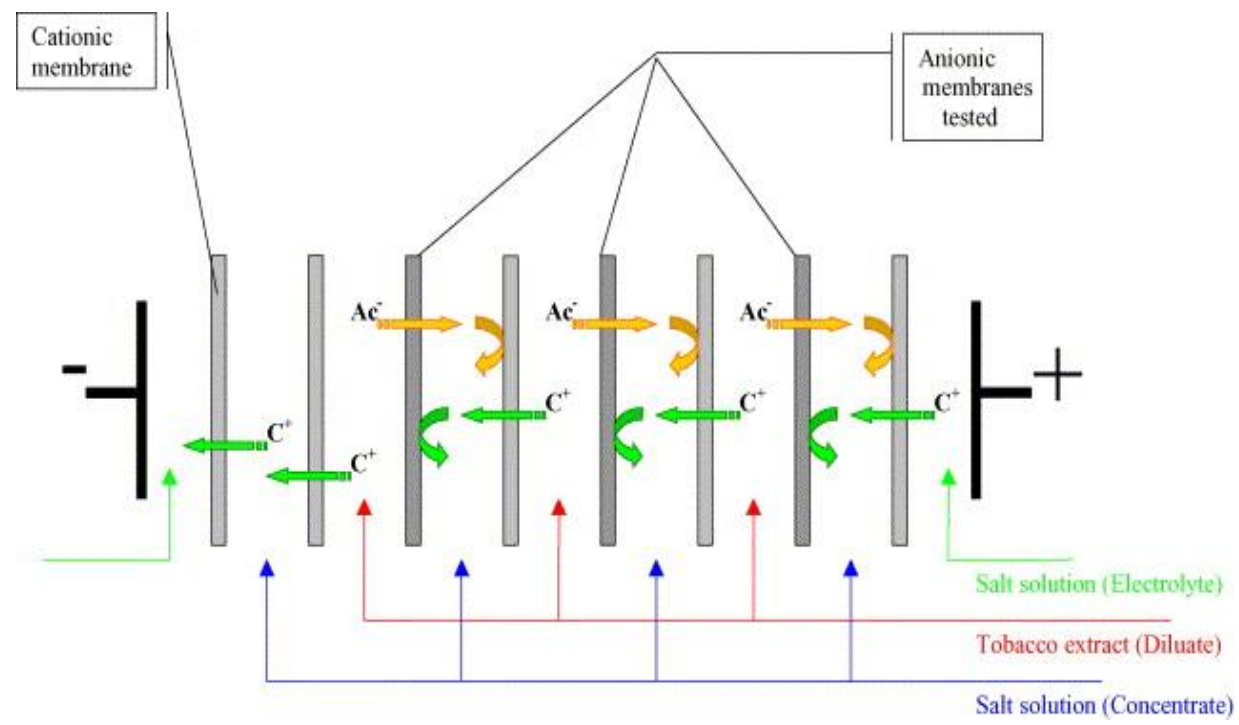

Fig. 5: Schematic diagram of electrodialysis system used for polyphenol separation from tobacco extract (adapted from [74])

hour of treatment. This study, in contrast to the study of Bazinet et al. [75], a better migration rate was observed using ultrafiltration membrane (1000 Da) in comparison to anion selective membranes. Therefore, it was concluded that separation and purification process using ED depend on the type (physicochemical and molecular cut off values) of the membrane used. Catechins are negatively charged at their initial $\mathrm{pH}$ (5.6 to 5.8) and thus migrate towards anode. In addition to isolating the polyphenols, another interesting application of EDFM is to concentrate polyphenols with antioxidant activity in fruit juices. The anthocyanins and proanthocyanins were concentrated to 52.9 and $34.8 \%$ respectively from natural cranberry juice by [78]. The authors also proposed a feasibility of direct integration of EDFM system in the cranberry juice processing plant in order to produce anthocyanins enriched cranberry juice. However, attenuation polyphenol concentration in the feed cranberry juice leads to the degradation of juice quality and membrane fouling during the treatment are major issues that should be solved for its successful application. Another study was carried out with larger volume of raw cranberry juice in the diluate compartment and smaller volume in the concentrate compartment [79]. This study demonstrated no change in physicochemical properties (sugar, organic acid, vitamin $\mathrm{C}$, color index $\mathrm{pH}$ and conductivity) of raw cranberry juice in the diluate solution. Another study were carried out by increasing the number of membrane stacking and using different volume ratio (diluate to concentrate side) of 30 which increased the anthocyanins content by $24 \%$ [80]. A continuous but single passage of cranberry juice in diluate side of EDFM system was found to increase the polyphenol content of another cranberry juice continuously circulated in the system. Moreover, titrable acidity was found to significantly decrease in the enriched juice thus increase the organoleptic characteristic.

However, above mentioned studies clearly demonstrated a problem related to the membrane fouling. Therefore, optimisation of process for a proper membrane type (both MWCO as well as membrane material), $\mathrm{pH}$, other electrodialytic parameters are needed. In addition, this process seems very promising for the separation and purification of polyphenols present in industrial byproducts such as grape seeds and marcs, olive oil wastewater, etc after an appropriate extraction process.

\section{Conclusion}

Significant improvements in polyphenol extraction have been made as compared to tradition method of solvent extraction. However, although the quantity solvent used is significantly reduced, the use of solvent at less concentration is vital for better productivity and yield. The studies clearly show that the efficiency of an extraction 


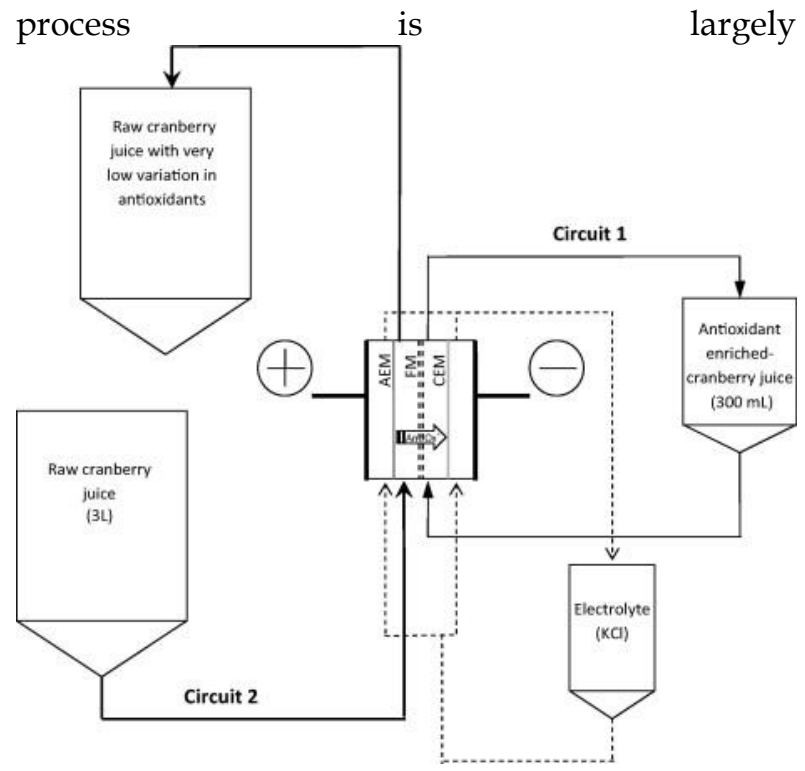

Fig. 6: Configuration of the EDFM cell and of the global system used to enrich cranberry juice polyphenols (anthocyanins). AEM: anionexchange membrane, FM: filtration membrane, CEM: cation-exchange membrane (adapted from [77]). dependent on the type of polyphenol to be extracted, its location in plant as well as type of plant material, selectivity and quality desired. The extraction process design therefore has to take into account of the source, the total yield, the productivity and selectivity. Moreover, more and more researches are inclined in the valorization of industrial by products such as from wine making process, olive oil mill and other fruit juices. This unquestionably shows both economical as well as environmental benefits. Once the polyphenol has been extracted and for the polyphenols that are already present in an aqueous solution such as juices and wines, different separation and purification could be employed. Ion exchange resins and pressure driven membrane process are widely used. However, electromembrane process known as electrodialysis with ultrafiltration could be a best alternative for the conventional fractionation methods because this is a green and very selective (no solvent used) technique and has no or less membrane fouling

\section{References}

1. Lopez AD, Murray CCJL: The global burden of disease, 1990-2020. Nat Med 1998, 4(11):1241-1243.

2. Wansink B, Westgren RE, Cheney MM: Hierarchy of nutritional knowledge that relates to the consumption of a functional food. Nutrition 2005, 21(2):264-268.

3. Manach C, Scalbert A, Morand C, Rémésy C, Jiménez L: Polyphenols: food sources and bioavailability. Am J Clin Nutr 2004, 79(5):727747.

4. Korhonen $\mathrm{H}$, Pihlanto A: Bioactive peptides: production and functionality. Int Dairy J 2006, 16(9):945-960.

5. Siriwardhana N, Kalupahana NS, MoustaidMoussa N, Se-Kwon K: Chapter 13 - Health Benefits of n-3 Polyunsaturated Fatty Acids: Eicosapentaenoic Acid and Docosahexaenoic Acid. In: Advances in Food and Nutrition Research. vol. Volume 65: Academic Press; 2012: 211-222.

6. Scalbert A, Johnson IT, Saltmarsh M: Polyphenols: antioxidants and beyond. Am J Clin Nutr 2005, 81(1):215S-217S.

7. Yu J, Ahmedna M, Goktepe I: Effects of processing methods and extraction solvents on concentration and antioxidant activity of peanut skin phenolics. Food Chem 2005, 90(12):199-206.

8. Turkmen N, Sari F, Velioglu YS: Effects of extraction solvents on concentration and antioxidant activity of black and black mate tea polyphenols determined by ferrous tartrate and Folin-Ciocalteu methods. Food Chem 2006, 99(4):835-841.

9. Cheynier Vr: Polyphenols in foods are more complex than often thought. Am J Clin Nutr 2005, 81(1):223S-229S.

10. Naczk M, Shahidi F: Extraction and analysis of phenolics in food. J Chromatogr 2004, 1054(1-2):95-111.

11. Tsao R: Chemistry and Biochemistry of Dietary Polyphenols. Nutrients 2010, 2(12):1231-1246.

12. El Gharras H: Polyphenols: food sources, properties and applications - a review. Int J Food Sci Tech 2009, 44(12):2512-2518.

13. Rodriguez-Mateos A, Rendeiro C, BergillosMeca T, Tabatabaee S, George TW, Heiss C, Spencer JP: Intake and time dependence of blueberry flavonoid-induced improvements in vascular function: a randomized, controlled, double-blind, crossover intervention study with mechanistic insights into biological activity. Am J Clin Nutr, 98(5):1179-1191.

14. Lorenz M: Cellular targets for the beneficial actions of tea polyphenols. Am J Clin Nutr 2013.

15. Clifford $\mathrm{MN}$, van der Hooft JJ, Crozier A: Human studies on the absorption, distribution, metabolism, and excretion of tea polyphenols. Am J Clin Nutr 2013.

16. Mustafa A, Turner C: Pressurized liquid extraction as a green approach in food and herbal plants extraction: A review. Anal Chim Acta 2011, 703(1):8-18. 
17. Hutzler P, Fischbach R, Heller W, Jungblut TP, Reuber S, Schmitz R, Veit M, Weissenböck G, Schnitzler J-P: Tissue localization of phenolic compounds in plants by confocal laser scanning microscopy. J Exp Bot 1998, 49(323):953-965.

18. Xu G, Ye X, Chen J, Liu D: Effect of Heat Treatment on the Phenolic Compounds and Antioxidant Capacity of Citrus Peel Extract. J Agric Food Chem 2006, 55(2):330-335.

19. Vinatoru M: An overview of the ultrasonically assisted extraction of bioactive principles from herbs. Ultrason Sonochem 2001, 8(3):303313.

20. Joana Gil-Chávez G, Villa JA, Fernando AyalaZavala J, Basilio Heredia J, Sepulveda D, Yahia EM, González-Aguilar GA: Technologies for Extraction and Production of Bioactive Compounds to be Used as Nutraceuticals and Food Ingredients: An Overview. Compr Rev Food Sci Food Saf 2013, 12:5-23.

21. Robbins RJ: Phenolic Acids in Foods: An Overview of Analytical Methodology. J Agric Food Chem 2003, 51(10):2866-2887.

22. Luque de Castro MD, García-Ayuso LE: Soxhlet extraction of solid materials: an outdated technique with a promising innovative future. Anal Chim Acta 1998, 369(12):1-10.

23. Luque de Castro MD, Priego-Capote F: Soxhlet extraction: Past and present panacea. $J$ Chromatogr 2010, 1217(16):2383-2389.

24. Denery JR, Dragull K, Tang CS, Li QX: Pressurized fluid extraction of carotenoids from Haematococcus pluvialis and Dunaliella salina and kavalactones from Piper methysticum. Anal Chim Acta 2004, 501(2):175181.

25. Vilkhu K, Mawson R, Simons L, Bates D: Applications and opportunities for ultrasound assisted extraction in the food industry - A review. Innov Food Sci Emerg Technol 2008, 9(2):161-169.

26. Chen F, Sun $Y$, Zhao G, Liao $X, H u X, W u ~ J$, Wang Z: Optimization of ultrasound-assisted extraction of anthocyanins in red raspberries and identification of anthocyanins in extract using high-performance liquid chromatography-mass spectrometry. Ultrason Sonochem 2007, 14(6):767-778.

27. Tiwari BK, Patras A, Brunton N, Cullen PJ, O'Donnell CP: Effect of ultrasound processing on anthocyanins and color of red grape juice. Ultrason Sonochem 2010, 17(3):598-604.

28. Corrales M, Toepfl S, Butz P, Knorr D, Tauscher B: Extraction of anthocyanins from grape by-products assisted by ultrasonics, high hydrostatic pressure or pulsed electric fields: A comparison. Innov Food Sci Emerg Technol 2008, 9(1):85-91.

29. Chemat F, Zill e H, Khan MK: Applications of ultrasound in food technology: Processing, preservation and extraction. Ultrason Sonochem 2011, 18(4):813-835.

30. Renoe BW: Microwave assisted extraction. American Laboratory 1994, 26:34-34.

31. Hayat $K$, Hussain $S$, Abbas S, Farooq U, Ding B, Xia S, Jia C, Zhang X, Xia W: Optimized microwave-assisted extraction of phenolic acids from citrus mandarin peels and evaluation of antioxidant activity in vitro. Sep Purif Technol 2009, 70(1):63-70.

32. Veggi PC, Martinez J, Meireles MAA: Fundamentals of Microwave Extraction. In: Microwave-assisted Extraction for Bioactive Compounds. Springer; 2013: 15-52.

33. Hayat $K$, Zhang X, Farooq U, Abbas S, Xia S, Jia C, Zhong F, Zhang J: Effect of microwave treatment on phenolic content and antioxidant activity of citrus mandarin pomace. Food Chem 2010, 123(2):423-429.

34. Hayat K, Zhang X, Chen H, Xia S, Jia C, Zhong F: Liberation and separation of phenolic compounds from citrus mandarin peels by microwave heating and its effect on antioxidant activity. Sep Purif Technol 2010, 73(3):371-376.

35. Ong E-S, Woo S-O, Yong Y-L: Pressurized liquid extraction of berberine and aristolochic acids in medicinal plants. $J$ Chromatogr 2000, 904(1):57-64.

36. Ong ES, Cheong JSH, Goh D: Pressurized hot water extraction of bioactive or marker compounds in botanicals and medicinal plant materials. J Chromatogr 2006, 1112(1-2):92-102.

37. Teo CC, Tan SN, Yong JWH, Hew CS, Ong ES: Pressurized hot water extraction (PHWE). $J$ Chromatogr 2010, 1217(16):2484-2494.

38. Palma M, Piñeiro Z, Barroso CG: Stability of phenolic compounds during extraction with superheated solvents. J Chromatogr 2001, 921(2):169-174.

39. Piñeiro $Z$, Palma $M$, Barroso CG: Determination of catechins by means of extraction with pressurized liquids. $J$ Chromatogr 2004, 1026(1-2):19-23.

40. Donsì F, Ferrari G, Pataro G: Applications of Pulsed Electric Field Treatments for the Enhancement of Mass Transfer from Vegetable Tissue. Food Eng Rev 2010, 2(2):109130.

41. López N, Puértolas E, Condón S, Álvarez I, Raso J: Effects of pulsed electric fields on the extraction of phenolic compounds during the fermentation of must of Tempranillo grapes. Innov Food Sci Emerg Technol 2008, 9(4):477-482.

42. Puértolas E, Saldaña G, Condón S, Álvarez I, Raso J: Evolution of polyphenolic compounds in red wine from Cabernet Sauvignon grapes processed by pulsed electric fields during aging in bottle. Food Chem 2010, 119(3):10631070.

43. Delsart C, Ghidossi R, Poupot C, Cholet C, Grimi N, Vorobiev E, Milisic V, Peuchot MM: 
Enhanced Extraction of Valuable Compounds from Merlot Grapes by Pulsed Electric Field. Am J Enol Viticult 2012.

44. López N, Puértolas E, Hernández-Orte P, Ignacio Álvarez I, Raso J: Effect of a pulsed electric field treatment on the anthocyanins composition and other quality parameters of Cabernet Sauvignon freshly fermented model wines obtained after different maceration times. LWT - Food Sci Technol 2009, 42(7):12251231.

45. Perrut M: Supercritical fluid applications: Industrial developments and economic issues. Ind Eng Chem Res 2000, 39(12):45314535.

46. Herrero M, Cifuentes A, Ibanez E: Sub-and supercritical fluid extraction of functional ingredients from different natural sources: Plants, food-by-products, algae and microalgae: A review. Food Chem 2006, 98(1):136-148.

47. Le Floch F, Tena MT, Ríos A, Valcárcel M: Supercritical fluid extraction of phenol compounds from olive leaves. Talanta 1998, 46(5):1123-1130.

48. Lu Y, Ma W, Hu R, Dai X, Pan Y: Ionic liquidbased microwave-assisted extraction of phenolic alkaloids from the medicinal plant Nelumbo nucifera Gaertn. J Chromatogr 2008, 1208(1-2):42-46.

49. Ballard TS, Mallikarjunan P, Zhou K, O'Keefe $\mathrm{S}$ : Microwave-assisted extraction of phenolic antioxidant compounds from peanut skins. Food Chem 2010, 120(4):1185-1192.

50. Celia M. Librán LM, Esperanza M. GarciaCastello, Daniel Vidal-Brotons: Polyphenol extraction from grape wastes: Solvent and $\mathrm{pH}$ effect. Agric Sci 2013, 9B:56-62.

51. Oancea S, Stoia M, Coman D: Effects of Extraction Conditions on Bioactive Anthocyanin Content of Vaccinium Corymbosum in the Perspective of Food Applications. Procedia Eng 2012, 42(0):489-495.

52. Li BB, Smith B, Hossain MM: Extraction of phenolics from citrus peels: II. Enzymeassisted extraction method. Sep Purif Technol 2006, 48(2):189-196.

53. Onofrejová L, Vašíčková J, Klejdus B, Stratil P, Mišurcová L, Kráčmar S, Kopecký J, Vacek J: Bioactive phenols in algae: The application of pressurized-liquid and solid-phase extraction techniques. J Pharm Biomed Anal 2010, 51(2):464-470.

54. Chen XJ, Guo BL, Li SP, Zhang QW, Tu PF, Wang YT: Simultaneous determination of 15 flavonoids in Epimedium using pressurized liquid extraction and high-performance liquid chromatography. J Chromatogr 2007, 1163(1-2):96-104.

55. Puértolas E, López N, Saldaña G, Álvarez I, Raso J: Evaluation of phenolic extraction during fermentation of red grapes treated by a continuous pulsed electric fields process at pilot-plant scale. J Food Eng 2010, 98(1):120125.

56. A Rostagno Mc, Araújo JMA, Sandi D: Supercritical fluid extraction of isoflavones from soybean flour. Food Chem 2002, 78(1):111117.

57. Kitzberger CSG, Smânia Jr A, Pedrosa RC, Ferreira SRS: Antioxidant and antimicrobial activities of shiitake (Lentinula edodes) extracts obtained by organic solvents and supercritical fluids. J Food Eng 2007, 80(2):631638.

58. Corrales M, GarcÃ-a AFn, Butz P, Tauscher B: Extraction of anthocyanins from grape skins assisted by high hydrostatic pressure. J Food Eng 2009, 90(4):415-421.

59. Briones-Labarca V, Plaza-Morales $M_{r}$ Giovagnoli-Vicuña C, Jamett F: High hydrostatic pressure and ultrasound extractions of antioxidant compounds, sulforaphane and fatty acids from Chilean papaya (Vasconcellea pubescens) seeds: Effects of extraction conditions and methods. LWT - Food Sci Technol 2015, 60(1):525-534.

60. Jun $X$ : Caffeine extraction from green tea leaves assisted by high pressure processing. $J$ Food Eng 2009, 94(1):105-109.

61. Pinela J, Prieto MA, Barros L, Carvalho AM, Oliveira MBPP, Saraiva JA, Ferreira ICFR: Cold extraction of phenolic compounds from watercress by high hydrostatic pressure: Process modelling and optimization. Sep Purif Technol 2018, 192:501-512.

62. Ottens M, Chilamkurthi S, Rizvi S (eds.): Advances in process chromatography and applications in the food, beverage and nutraceutical industries; 2010.

63. Wang L, Gong L-H, Chen C-J, Han H-B, Li H$\mathrm{H}$ : Column-chromatographic extraction and separation of polyphenols, caffeine and theanine from green tea. Food Chem 2012, 131(4):1539-1545.

64. Andersen $Ø \mathrm{M}$, Fossen $\mathrm{T}$, Torskangerpoll $\mathrm{K}$, Fossen A, Hauge U: Anthocyanin from strawberry (Fragaria ananassa) with the novel aglycone, 5-carboxypyranopelargonidin. Phytochemistry 2004, 65(4):405-410.

65. Vitrac $X$, Castagnino $C$, Waffo-Téguo $P$, Delaunay J-C, Vercauteren J, Monti J-P, Deffieux G, Mérillon J-M: Polyphenols Newly Extracted in Red Wine from Southwestern France by Centrifugal Partition Chromatography. I Agric Food Chem 2001, 49(12):5934-5938.

66. Feng L, Zhao F: Separation of Polyphenols in Tea on Weakly Acidic Cation-Exchange Gels. Chromatographia 2010, 71(9-10):775-782.

67. Nawaz H, Shi J, Mittal GS, Kakuda Y: Extraction of polyphenols from grape seeds and concentration by ultrafiltration. Sep Purif Technol 2006, 48(2):176-181. 
68. D. Liu, E. Vorobiev, R. Savoire, Lanoisellé J-L: Extraction of polyphenols from grape seeds by unconventional methods and extract concentration through polymeric membrane. In: 11th International Congress on Engineering and Food (ICEF 11); Athens, Greece. 2011.

69. Russo C: A new membrane process for the selective fractionation and total recovery of polyphenols, water and organic substances from vegetation waters (VW). J Membr Sci 2007, 288(1-2):239-246.

70. Garcia-Castello E, Cassano A, Criscuoli A, Conidi C, Drioli E: Recovery and concentration of polyphenols from olive mill wastewaters by integrated membrane system. Water Res 2010, 44(13):3883-3892.

71. Lawson KW, Lloyd DR: Membrane distillation. J Membr Sci 1997, 124(1):1-25.

72. El-Abbassi A, Hafidi A, García-Payo M, Khayet M: Concentration of olive mill wastewater by membrane distillation for polyphenols recovery. Desalination 2009, 245(1):670-674.

73. Susanto H, Feng Y, Ulbricht M: Fouling behavior of aqueous solutions of polyphenolic compounds during ultrafiltration. J Food Eng 2009, 91(2):333-340.

74. Aider M, de Halleux D, Bazinet L: Potential of continuous electrophoresis without and with porous membranes (CEPM) in the bio-food industry: review. Trends Food Sci Technol 2008, 19(7):351-362.

75. Bazinet L, DeGrandpré Y, Porter A: Electromigration of tobacco polyphenols. Sep Purif Technol 2005, 41(1):101-107.

76. Bazinet L, DeGrandpré Y, Porter A: Enhanced tobacco polyphenol electromigration and impact on membrane integrity. J Membr Sci 2005, 254(1-2):111-118.

77. Labbé D, Araya-Farias M, Tremblay A, Bazinet L: Electromigration feasibility of green tea catechins. J Membr Sci 2005, 254(1-2):101-109.

78. Bazinet L, Cossec $\mathrm{Cl}$, Gaudreau Hln, Desjardins Y: Production of a Phenolic Antioxidant Enriched Cranberry Juice by Electrodialysis with Filtration Membrane. J Agric Food Chem 2009, 57(21):10245-10251.

79. Bazinet L, Brianceau S, Dubé P, Desjardins Y: Evolution of cranberry juice physicochemical parameters during phenolic antioxidant enrichment by electrodialysis with filtration membrane. Sep Purif Technol 2012, 87(0):31-39.

80. Husson E, Araya-Farias M, Desjardins Y, Bazinet L: Selective anthocyanins enrichment of cranberry juice by electrodialysis with ultrafiltration membranes stacked. Innov Food Sci Emerg Technol 2013, 17(0):153-162 